\title{
Vertebral deformity corrected by bracing: retrospective selected case series of 10 scoliosis patients treated with a RSC Brace Manuel Rigo*, Monica Villagrasa and Gloria Quera-Salvá
}

Address: E. Salvá Institute. Barcelona, Spain

* Corresponding author

from $5^{\text {th }}$ International Conference on Conservative Management of Spinal Deformities

Athens, Greece. 3-5 April 2008

Published: 15 January 2009

Scoliosis 2009, 4(Suppl I):O45 doi:I0.II86/I748-7|6|-4-SI-O45

This abstract is available from: http://www.scoliosisjournal.com/content/4/SI/O45

(C) 2009 Rigo et al; licensee BioMed Central Ltd.

\section{Background}

Bracing can prevent curve progression in Idiopathic Scoliosis. Compliance and in-brace correction predict the end result. Part time, full time or even night time bracing may result in excellent in-brace correction. This is associated with a progressive correction of the spinal and trunk deformity as well as a correction of the vertebral deformity. This 10 patient series demonstrates a clear correction of the vertebral, spinal and trunk deformity.

\section{Materials and methods}

Retrospective selected case series of 10 patients (8 F, $2 \mathrm{M}$ ) diagnosed with IS, with a minimum age of 5 years and a maximum of 13, all of them treated with a RSC brace. Curve pattern: 7 thoracic, 1 thoracic double major and 2 thoracolumbar. Minimum observation time was 1 year and 3 months and maximum 5 years 5 months. Mean Cobb angle was $36^{\circ}\left(25^{\circ}-47^{\circ}\right)$. All the patients showed an in-brace correction in their first brace $>45 \%$.

\section{Results and conclusion}

Results are presented case by case. After a minimum of 1 year of observation all the patients showed a correction of the vertebral wedging in the apex $\geq 50 \%$. Four patients have finished the treatment, and they maintain a correction of the main curve higher than $10^{\circ}$. All the patients showed a marked correction of the trunk asymmetry. Some case reports have shown that correction of the vertebral deformity is possible. A retrospective series of selected cases demonstrate that this phenomenon is not rare. These results support the 'vicious cycle model'.

\section{References}

I. Chêneau J, et al:: Wedge vertebrae normalization in congenital scoliosis due to the application of external forces by brace. Scoliosis 2007, 2(suppI I):S29.

2. Weiss HR, Rigo M: The Chêneau Concept of Bracing - Actual Standards. Stud Health Technol Inform 2008, 135:291-302.

3. Rigo M, Weiss HR: The Chêneau Concept of Bracing - Biomechanical aspects. Stud Health Technol Inform 2008, I35:303-19. 